\title{
Implementation of arsenic mitigation: insights from Araihazar and Matlab - two extensively studied areas in Bangladesh
}

\author{
K.M. Ahmed ${ }^{1}$, A. van Geen ${ }^{2}$ \& P. Bhattacharya ${ }^{3}$ \\ ${ }^{1}$ Department of Geology, University of Dhaka, Dhaka, Bangladesh \\ ${ }^{2}$ Lamont Doherty Earth Observatory, Columbia University, New York, USA \\ ${ }^{3}$ KTH-International Groundwater Arsenic Research Group, Department of Sustainable Development, \\ Environmental Science and Engineering, KTH Royal Institute of Technology, Stockholm, Sweden
}

\begin{abstract}
Despite many efforts over the last 25 years, millions of people are still drinking groundwater having arsenic above Bangladesh and World Health Organization limits. This can be linked, to some extent, to a lack of pragmatic policies and implementation strategies. Important lessons have been learned from extensive studies in Araihazar and Matlab in Bangladesh. Also better mitigation strategies for reducing arsenic exposure have been demonstrated at both locations. New policy and mitigation strategies should focus on mapping using mobile technology for village scale mapping. Dissemination of test result is extremely important in increasing awareness of the users and a new three-color scheme (Blue, Green, Red corresponding to $<10,10-50$, and $>50 \mu \mathrm{g} \mathrm{L}^{-1}$ ) instead of existing Red-Green color scheme should be adopted to lower arsenic intake. Safe wells can be installed at appropriate locations and depth by combining hydrogeological and social criteria aided by applications-based score ranking.
\end{abstract}

\section{INTRODUCTION}

Arsenic contamination of groundwater remains a major problem in access to safe water in Bangladesh although various arsenic mitigation plans have been tested and implemented in the country over the last 25 years. About 20 million people are still drinking water with more than $50 \mu \mathrm{g} \mathrm{L}^{-1}$ arsenic while the number increases to 40 million is $10 \mu \mathrm{g} \mathrm{L}^{-1}$ is considered as the safe limit. Inability to provide safe water to a large number of people is linked with the issue of pragmatic implementable policy of arsenic mitigation (Pfaff et al., 2017). Various national and local level studies have focused on scientific and societal aspects in prioritizing arsenic mitigation in Bangladesh. Araihazar in Narayangaj and Matlab in Chandpur are the two extensively studied areas located in two different types arsenic exposure scenarios (Fig. 1) where mitigation has been designed based on hydrogeological and socio-economic aspects. Lessons learned from the two areas can help in upgrading policies and implementation plans for arsenic in areas where people are still drinking arsenic above safe limits (Hossain et al., 2014; van Geen et al., 2016).

\section{METHODS}

Occurrences and distribution of arsenic has been thoroughly investigated in Araihazar in relation to a health impact study by a multidisciplinary team of scientists from Columbia University, USA and University of Dhaka Bangladesh since 2001. A detailed study has also been carried out in Matlab area by a consortium of the Royal Institute of Technology, Sweden; University of Dhaka and NGO Forum for Public Health, Bangladesh. Both the studies included blanket testing of arsenic; detailed subsurface mapping; analysis of arsenic and other water quality parameters; investigations on spatial, vertical and temporal variations of groundwater arsenic; association between sediment color and groundwater chemistry; village scale mapping of arsenic; installation of safe wells based on sediment color; exploration of intermediate aquifer as a source of safe water. Detailed and accurate mapping at village scales of locations of unsafe wells along with geology were studied for installing safe well in Araihazar; whereas, socio-economic status of the villagers was also recorded for placing safe wells in Matlab.

\section{RESULTS AND DISCUSSION}

Blanket testing and mapping using Mobile Technology: Studies in Araihazar showed that there are many untested wells with arsenic concentrations above allowable limit and those wells are being used by the local communities. There is a need for national blanket testing using smart technologies and apps so that data can be stored and used for mapping down to village scale.

Not just Red and Green, we need a Blue: It is very important to display test results on wells. Red and Green color of well spouts were used in earlier testing program for marking safe and unsafe wells according to Bangladesh standards. As now there is more 


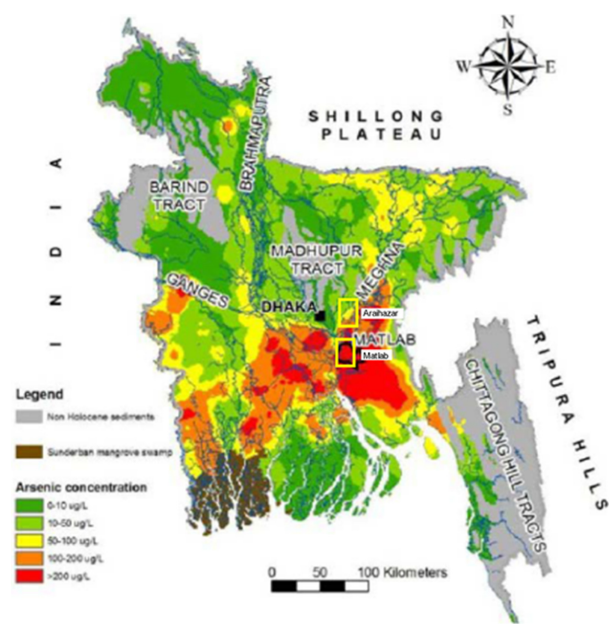

Figure 1. Location of Araihazar and Matlab on arsenic distribution map of Bangladesh (modified from Hossain et al., 2014).

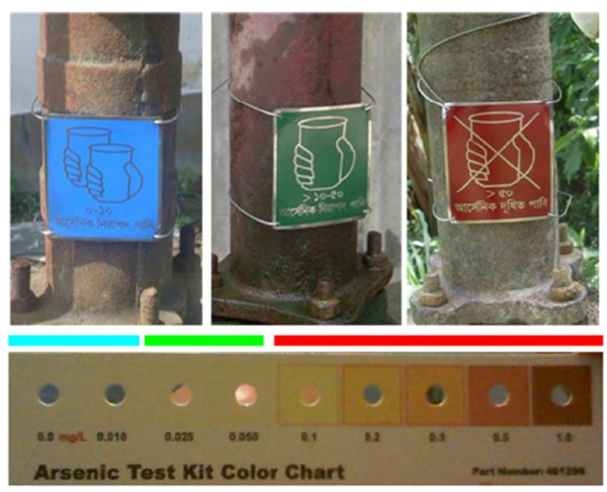

Figure 2. Three color placards used in Araihazar for disseminating test results (from van Geen et al., 2014).

information regarding the relative health risk of 50 and $10 \mu \mathrm{g} \mathrm{L}^{-1}$, users must be informed about it. This can be achieved by adopting a three-color system instead of two by including Blue for wells up to $10 \mu \mathrm{g} \mathrm{L}^{-1}$ (Fig. 2).

Village scale implementation plan (VSIP): Studies both in Araihazar and Matlab demonstrated that the best way to plan for arsenic mitigation is through village scale mapping of spatial and vertical variations. Social criteria can be added to the arsenic map to ensure safe water to the poorer communities.

Score-based safe well location: Relative scoring for various locations can be introduced by using mobile phone apps. This can ensure better location of safe wells for providing maximum coverage.

Not only STW and HTW, there can be IDTW: It has been found at both the study area that there is an intermediate aquifer between 100 to $200 \mathrm{~m}$ at most villages. If intermediate deep wells (IDTW) are installed targeting this depth, lot of resource can be compared

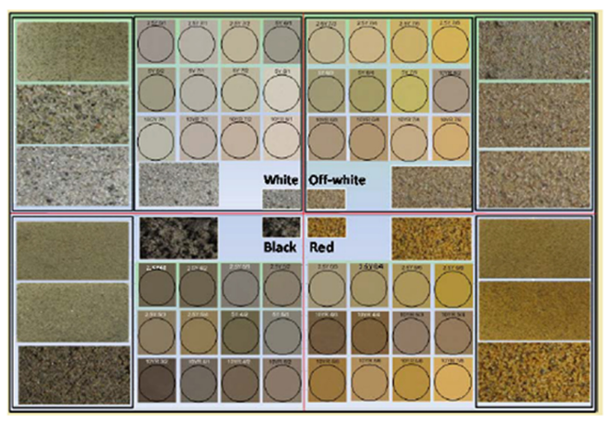

Figure 3. Sediment color tool for use by the local drillers in targeting arsenic safe aquifers (from Hossain et al., 2014).

to installation of deep wells only at depth more than $200 \mathrm{~m}$.

Capacity building of drillers, the Sediment Color Tool: Sediment color has links with arsenic, manganese and iron concentrations in groundwater. Local drillers are aware of this but their capacity can be further enhanced by providing simple tools like the sediment color tool developed from the Matlab study (Fig. 3).

\section{CONCLUSIONS}

Key findings from two extensive studies should be used to update and harmonize arsenic mitigation policies. Issues that need to be included in any new policy of arsenic mitigation include promotion and regulation of commercial tube-well testing; launching national campaign to update households on risks of arsenic exposure; dissemination of arsenic-safe depth at the village level and capacity building at local levels to encourage drillers and households to target lowarsenic aquifers. Future safe tube-well installations should be based on geochemical as well as hydrogeological suitability and should take into account social factors in order to maximize impact.

\section{REFERENCES}

Hossain, M., Bhattacharya, P., Frape, S.K., Jacks, G., Islam, M.M., Rahman, M.M., Hasan, M.A. \& Ahmed, K.M. 2014. Sediment color tool for targeting arsenic-safe aquifers for the installation of shallow drinking water tubewells. Sci. Total Environ. 493: 615-625.

Pfaff, A.A. Walker, S., Ahmed, K.M. \& A. van Geen 2017. Reduction in exposure to arsenic from drinking wellwater in Bangladesh limited by insufficient testing and awareness. J. Wat. San. Hyg. Dev. 7(2): 331-339.

van Geen, A., Sumon, E.B.A., Pitcher, L., Mey, J.L., Ahsan, H., Graziano, J.H. \& Ahmed, K.M. 2014. Comparison of two blanket surveys of arsenic in tubewells conducted 12 years apart in a $25 \mathrm{~km}^{2}$ area of Bangladesh. Sci. Total Environ. 488-489: 484-492.

van Geen, A., Ahmed, K.M., Ahmed, E.B., Choudhury, I., Mozumder, M.R., Bostick, B.C. \& Mailloux, B.J. 2016. Inequitable allocation of deep community wells for reducing arsenic exposure in Bangladesh. J. Wat. San. Hyg. Dev. 6(1): $142-150$. 